Collective Interviewing: A transactive memory approach towards identifying signs of truthfulness

Zarah Vernham $^{1}$

Aldert Vrij

Sharon Leal

Samantha Mann

Jackie Hillman

University of Portsmouth

${ }^{1}$ Correspondence concerning this article should be addressed to: Zarah Vernham, University of Portsmouth, Psychology Department, King Henry Building, King Henry 1 Street, Portsmouth, PO1 2DY, UK, or via e-mail: zarah.vernham@port.ac.uk. 


\begin{abstract}
Group interviewing has been neglected in the deception literature, yet it coincides with recent collective memory research. The present experiment applied the transactive memory theory to a collective interviewing situation and explored whether signs of truthfulness emerged through measuring joint memory recall. Truth-tellers were real couples who had been in a relationship for at least one year and cohabiting. Lying pairs were friends who pretended to be in a relationship for at least one year and cohabiting. All couples were interviewed in their pairs about their 'real' or 'fictitious' relationship. It was found that truth-telling pairs posed questions to one another, provided cues to one another, handed over remembering responsibility, and finished each others' sentences significantly more than lying pairs, supporting the idea that real couples have a transactive memory system, unlike pretend couples. Implications for a collective interview approach that considers memory within deception detection are discussed.
\end{abstract}

Keywords: deception, truthfulness, group interviewing, transactive memory, collaborative recall. 


\section{Collective Interviewing: A transactive memory approach towards identifying signs of truthfulness}

Cognitive psychology, specifically memory research, has developed over recent years through the exploration of not only individual memory, but also collaborative learning, collaborative remembering, and joint recall (e.g., Barnier \& Sutton, 2008; Blumen, Rajaram \& Henkel, 2013; Harris, Paterson \& Kemp, 2008). Collective memory examines the social nature of memory by treating past experiences and events as memories shared with others (Barnier \& Sutton, 2008; Hirst \& Manier, 2008; Rajaram, 2011). It explores how individuals collectively recall information together (Rajaram \& Pereira-Pasarin, 2010). The research suggests that group collaboration can aid memory through cross-cueing (where members of the group provide cues to one another that increase recall) and error-pruning (where feedback from other members of the group create discussions that make people realise their recall errors) (Rajaram, 2011; Ross, Blatz \& Schryer, 2008).

Deception research has primarily focused on interviewing single suspects despite the fact that crimes are frequently committed by pairs or multiple offenders (Van Mastrigt \& Farrington, 2009; $\mathrm{M}^{\mathrm{c}}$ Gloin \& Piquero, 2009). Therefore, it seems relevant to explore how group members lie or tell the truth together. Collective interviewing is a new approach to lie detection that coincides with the current trend in collective memory research by focusing on the joint recall of events when two or more individuals are interviewed together at the same time. Although suspects are typically interviewed individually and immediately separated from their group members within police interview settings (Kassin \& Gudjonsson, 2004), there are alternative situations whereby it would be more suitable, timely and convenient to interview group members simultaneously, for example, at road border controls where cars containing several people are checked, or at security checkpoints (e.g., airports). Importantly, collective interviewing is already part of some existing procedures. For example, in Canada 
immigration officers at airports carry out collective interviews, and in the United Kingdom couples are expected, at one potential stage, to be interviewed simultaneously in order to marry and achieve British Citizenship.

Four recent studies have illustrated the clear potential for using collective interviewing to elicit social cues to deceit, specifically communication and interaction cues. Vrij et al. (2012) examined verbal communication cues and found that pairs of truth-tellers interrupted and corrected each other more than pairs of liars, as well as adding more information to each other's accounts. Jundi et al. (2013a) examined nonverbal communication cues and found that pairs of liars made more eye contact with the interviewer than pairs of truth-tellers, whereas pairs of truth-tellers looked more at each other than pairs of liars. Driskell, Salas and Driskell (2012) investigated the social indicators of deception within a transactive memory framework and found that pairs of truth-tellers illustrated more synchrony in behaviour and exhibited more interactions (e.g., mutual eye gaze and verbal transitions) than pairs of liars. Finally, Jundi, Vrij, Hope, Mann and Hillman (2013b) applied the theory of transactive memory to a timeline task in which pairs had to work together to illustrate on paper the length of time each part of their experimental task had taken. The authors found that truth-telling pairs, in comparison to lying pairs, posed more questions to one another during the timeline task. These four studies show that a collective approach can generate discrepancies between pairs of truth-tellers and pairs of liars in the way they communicate.

The aim of the present experiment was to apply a collective interviewing approach to the setting of being interviewed simultaneously to achieve British Citizenship. Similar to the studies by Driskell et al. (2012) and Jundi et al. (2013b), the present experiment explored differences between truth-telling and lying couples within the context of transactive memory. However, the present experiment differed from the previous studies in some important ways. 
First, Driskell et al. (2012) focused on generic verbal transitions defining them broadly in terms of back- and fourth- verbal exchange (i.e., the number of times an individual elaborated or responded immediately after their partner). Conversely, the present experiment explored the specific types of verbal transitions used by the pairs, focusing on the fundamental memory cues that emerge through collaborative recall and remembering and that may be an indication of truthfulness. Second, whilst Driskell et al. (2012) and Jundi et al. (2013b) both measured posing questions to one another, we thought it to be relevant to replicate this measurement within a different context in the present experiment. That is, whereas Driskell et al. (2012) used a brief investigative interview (similar to that which might occur during initial screenings at security checkpoints) and Jundi et al. (2013b) measured the number of questions posed to one another whilst the pair completed a timeline task, the present experiment measured the frequency of questions posed to one another during a lengthy immigration-type interview. Third, an extra factor was added to the present experiment to explore the influence of question type, an area that has been investigated in previous deception research and been shown to be important. For example, Vrij et al. (2009) found that asking unanticipated questions about central topics increased the discrepancies between pairs of liars' statements because they had not been able to prepare answers to these questions. These discrepancies were not found between pairs of truth-tellers' statements because they were relying purely on memory. To take the expectedness of the interview questions into consideration, the present experiment split the interview into anticipated questions (which pairs may have planned for) and unanticipated interview questions (which negate the benefit of planning for the interview).

\section{Transactive Memory}

The theory of Transactive Memory is concerned with how groups (and individuals) process and structure information with regard to past events. The theory was developed to 
describe how people in close intimate relationships share cognition and 'think together' (Wegner, 1987). It proposes that people in close relationships have a specialised memory system or 'division of labour' for encoding, storing and retrieving information (Hollingshead, 1998; Wegner, 1987). This is particularly relevant to the present experiment whereby 'real' (truth-telling) or 'fictitious' (lying) couples were the focus.

Transactive memory theory postulates that people who are actually in a close relationship (truth-tellers) share remembering, also knowing each other's memory expertise (i.e., each person knows what they are to remember as well as what the other person in the relationship is to remember) (Hollingshead \& Brandon, 2003). This results in a transactive memory system that is greater than the total of all of the individual memories (Wegner, Erber \& Raymond, 1991; Wegner, Giuliano \& Hertel, 1985). Over time, the individuals within the pair (couple) update their transactive memory systems, improving the system and making it more efficient. This transactive memory system is active at all three stages of memory formation and recall: Encoding, storing, and retrieving. First, when information is encoded regarding a shared experience responsibility for information is divided and shared between the members of the pair (Hollingshead \& Brandon, 2003). Second, when information is stored, each individual within the pair has remembering responsibilities, knowing what their role is, what they are to remember, and what information their partner has access to (Wegner et al., 1991). Third, retrieval of information is social and interactive as the individuals within the pair communicate considerably with one another to retrieve as much information as possible. The communication with one another and the discussion of incoming information enhances their individual recollections. Hollingshead (1998) refers to the transaction memory search whereby group members who have experienced a past shared event make instinctive use of their transactive memory system to increase recall by posing questions to one another to check information or find out information, cuing one another to remind one another of 
further information, and handing over remembering responsibility to who best remembers that part of the event. These interactive and communicative behaviours between the group members help one another tap into their different memory domains and trigger further information, increasing recall. Consequently, it should be the truth-telling couples in the present experiment that demonstrate the use of a transactive memory system, and therefore display these fundamental interactive and communicative behaviours during their joint recall.

Conversely, pairs of individuals who are fabricating their relationship and inventing (or at least partially inventing) shared events will need to mislead or deceive investigators, and in order for these lying pairs to be able to do this, they will need to illustrate the same pattern of responses as the truth-telling pairs. This will be difficult for them to do without the shared memory system for encoding, storing and retrieving information that truth-telling pairs have. Research has shown that deceptive communication is characterised by the absence of social and interactive behaviours and that this is likely to be due to the fact that at the time of recall deceptive pairs do not retrieve information from a transactive memory system, unlike truth-telling pairs (Driskell et al., 2012). Instead, lying pairs will rely on a combination of individual processes, which means that each member needs to rely on their individual cognitive ability to create a story that makes sense and matches with what the other individual in their pair is saying (Hintz, 1990). Retrieval of information in lying pairs is therefore an individual cognitive task which will result in lying pairs exhibiting fewer interactions as they recall their fabricated story (Driskell et al., 2012; Vrij et al., 2012), and only providing prepared answers to expected questions (Granhag, Strömwall \& Jonsson, 2003; Strömwall, Granhag \& Jonsson, 2003; Vrij, Mann, Leal \& Granhag, 2010). Additionally, lying pairs will focus on appearing credible when investigated (DePaulo, LeMay \& Epstein, 1991; DePaulo et al., 2003), and due to the misconceptions held by people with regards to the cues that imply deceit (Vrij, 2008a), the lying pairs in particular will avoid 
certain behaviours, e.g., correcting and interrupting one another (Vrij et al., 2012), posing questions to one another (Driskell et al., 2012), and admitting a lack of memory (Porter \& Yuille, 1996). This again will make the memory cues arising from transactive memory more apparent in truth-telling pairs who believe the truth will shine through ('illusion of transparency'; Gilovich, Savitsky, \& Medvec, 1998) and are not as concerned with appearing credible, and hence do not avoid particular communications and interactions.

To summarise, truth-telling pairs will encode, store, and recall information through a transactive memory system, whereas lying pairs will encode, store and recall information at an individual level. Consequently, two people recalling an actual jointly experienced event will do so in a different manner than two people who are attempting to recall a fabricated event. Thus, collective interviewing should elicit differences between pairs of truth-tellers and pairs of liars in the transactional information search (Hollingshead, 1998) and that signs of truthfulness as a result of memory differences between pairs of truth-tellers and pairs of liars can be detected. The focus of the present experiment was verbal transitions, but more specifically, it considered four different types of verbal transitions that pairs illustrate when retrieving information through their transactive memory systems. These four verbal transitions were: Posing questions to one another, providing cues to one another, handing over of remembering responsibility, and finishing each other's sentences.

\section{Hypotheses}

Overall, truth-telling pairs are expected to exhibit more of each type of verbal transition than the lying pairs when interviewed together about their 'relationship'. Hence, the present experiment focuses on signs of truthfulness as opposed to signs of deceit. Based on the frequency of each type of verbal transition during the interview, it was hypothesised that truth-telling couples will pose questions to one another to check information or find out information significantly more than lying pairs (Hypothesis 1), provide cues to one another 
significantly more than lying pairs (Hypothesis 2), hand over remembering responsibility significantly more than lying pairs (Hypothesis 3), and finish each other's sentences significantly more than lying pairs (Hypothesis 4). The finishing of each other's sentences has been suggested by us as the authors as an important extra cue to measure, because based on the transactive memory literature (e.g. Hollingshead, 1998; Hollingshead \& Brandon, 2003; Wegner et al., 1991) it is clear that the truth-telling couples will have knowledge of what one another is saying and further going to say. Consequently, truth-telling pairs will interrupt one another and automatically complete each other's sentences, which lying pairs will not do through fear that these interruptions will raise suspicion and imply deceit (Vrij et al., 2012).

Additionally, the present experiment will explore the effect that the Expectedness of the interview question has on the frequency of each of the verbal transitions. Previous research has found that asking unexpected interview questions surprises liars and negates the benefit of planning for the interview, requiring the liars to 'think on the spot' (Vrij et al., 2010). Consequently, more cues to deceit will emerge from liars responses to unanticipated questions compared to anticipated questions which they are able to prepare for (DePaulo et al., 2003). Furthermore, pairs of liars interviewed individually show less overlap in their responses to unanticipated questions compared to anticipated questions (Vrij et al., 2009). In contrast, truth-tellers respond similarly to both anticipated and unanticipated questions, and when pairs of truth-tellers are interviewed individually they show similar amounts of overlap when responding to both anticipated and unanticipated questions. The findings above indicate the relevance of measuring the effect of Expectedness of the interview question. However, no hypothesis will be formulated because we are unsure how Expectedness will affect each of the verbal transitions when pairs of participants are interviewed collectively.

\section{Method}




\section{Participants}

Participants were recruited via online advertisements, the University of Portsmouth staff and student portals, and word of mouth. All participants were told prior to signing up to the study that it was an experiment investigating whether they could convince an interviewer that they were in a romantic relationship with their selected interview partner.

A total of 92 participants (45 males and 47 females) from the University of Portsmouth took part in this study. The mean age was 22.64 years $(S D=5.90)$. Truth-telling pairs $(\mathrm{N}=24)$ were real couples who had been in a relationship for at least one year and cohabiting. Lying pairs $(\mathrm{N}=22)$ were friends who were told only to take part as a pretend couple if they had never been intimate with one another and did not live together. The lying pairs had to be of the same sexual orientation; thus of the opposite sex to one another if they were both heterosexual and of the same sex if they were both homosexual. Of all 46 pairs who participated in this study, 45 were heterosexual and one was homosexual. The one homosexual pair was a lying pair.

\section{Design}

This experiment used a mixed design with Veracity (truth versus lie) as the betweensubjects factor and Expectedness (anticipated interview questions versus unanticipated interview questions) as the within-subjects factor. Posing questions to one another, providing cues to one another, handing over of remembering responsibility, and finishing each other's sentences were the dependent variables (i.e., the four verbal transitions measured).

\section{Procedure}

Upon arrival to the Psychology Department, all pairs were asked to go for coffee (paid for by the researchers) for approximately 30 minutes. They were instructed to prepare during coffee for the interview and talk about their 'real' or 'pretend' relationship, discussing 
(i) how they met, (ii) how they spend time together, and (iii) where they live (the interview then focused on these issues). They were also informed that they would be interviewed together at the same time. Therefore, if differences between truth-tellers and liars were to emerge, this would not be because the collective interview setting took the pairs by surprise. Once the pairs returned to the department and stated they were ready to be interviewed, they individually completed pre-interview questionnaires. These were completed to get an understanding of how much the pairs had prepared for the interview and whether the preparation discussions differed between truth-telling pairs and lying pairs. The pre-interview questionnaire asked participants to rate on 7-point Likert scales the thoroughness (ranging from [1] incomplete to [7] thorough), sufficiency (ranging from [1] insufficient to [7] sufficient), quality (ranging from [1] very poor to [7] very good), and usefulness (ranging from [1] = pointless to [7] = useful) of their preparation discussion. It also asked the participants to rate how much they discussed with their partner what to say during the interview (ranging from [1] not at all to [7] = thoroughly).

A collective interview in which pairs were interviewed together then took place. The interview was audio- and video- recorded. All interviews involved one interviewer who was blind to the veracity of the couple. The interview schedule comprised six interview questions (see Table 1). The task for all couples was to convince the interviewer that they were a bona fide couple who had been in a relationship for at least one year and were now living together. Thus real couples just had to tell the truth, whilst pretend couples had to describe a fabricated relationship.

To motivate participants to perform well during the experiment, they were told that if they were believed by the interviewer they would receive $£ 5$. However, if they were not believed they would receive no money and would be required to write a statement about their relationship with the other individual in their pair. To ensure that all participants were 
actually paid $£ 5$, the experimenter told them at the end of the experiment that the interviewer believed they were telling the truth.

Following participation, a post-interview questionnaire was completed individually and at this stage all participants were instructed to be truthful about their experience of the interview and the strategies they used. In this questionnaire, participants were asked to rate on a 7-point Likert scale from [1] not at all motivated to [7] extremely motivated, the extent to which they felt motivated to appear convincing during the interview. They were also asked to rate their confidence in receiving $£ 5$ and their confidence about whether or not they would have to write a statement (both on 7-point Likert scales from [1] none at all to [7] very likely). Additionally, participants were asked to rate on 7-point Likert scales (ranging from [1] easy to do to [7] difficult to do) the extent to which they found being interviewed collectively easy or difficult to do. Finally, to explore how honest participants reported to have been in the interview, they rated on scales from $0 \%$ to $100 \%$ with $10 \%$ intervals the extent to which they told the truth during the interview and the extent to which they lied during the interview.

Truth-tellers were asked an additional open question about how long, in number of months, they had been in a romantic relationship with their interview partner. This relationship length variable was used in correlational analyses along with each of the dependent variables as a means of examining whether or not relationship length was associated with any of the four verbal transitions, and therefore confounding the effect of Veracity.

Conversely, liars were given an additional post-interview questionnaire to explore whether they actually met the inclusion criteria and had not been in a previous intimate relationship with their interview partner. The first part of this questionnaire asked an open question about how long, in number of months, the liars had been friends with one another. It 
then measured on four different 7-point Likert scales how they rated their friendship with their interview partner. This included questions about friendliness (ranging from [1] strangers to [7] best friends), intimacy (ranging from [1] distant to [7] intimate), importance (ranging from [1] unimportant to [7] important) and trustfulness (ranging from [1] distrusting to [7] trusting). Each individual that made up the lying pair gave their own rating for each of the four questions. The ratings from the four questions were then added together to give a total friendship-closeness rating for each individual within each pair. The average rating for each pair was obtained providing an overall friendship-closeness score for each lying pair. The friendship length and the friendship-closeness variables were inputted into correlational analyses along with each of the dependent variables to determine whether friendship length or friendship-closeness were associated with any of the four verbal transitions, and therefore confounding the effect of Veracity.

\section{Coding}

The interview transcripts were coded by a rater who was blind to the hypotheses and veracity status of the pairs. All four dependent variables (verbal transitions) were coded for all six interview questions separately and the total frequency that each variable occurred within the interview across the six questions was calculated for each pair.

Posing questions to one another was the number of times a member of the pair asked their interview partner a question, usually to check information or find out information (e.g., "Did we watch two movies that night or just one?" or "Was I working that day?"). Providing cues to one another was the number of times members of the pair cross-cued - That is when one member of the pair stated something that reminded their interview partner of additional information (e.g., one member of the pair might say "We watched something but I can't remember the name of it now", and the other member of the pair might say "The thing we were watching was a soap called Chalkhill Lives", which results in the first member of the 
pair then responding with a phrase, such as "Oh yeah, I remember now"). An exchange such as the previous example would be counted as one cross-cue. The handing over of remembering responsibility was the number of times members of the pair passed over the conversation depending on who best remembers what. Participants would state that they do not remember the information as thoroughly as their partner so will automatically ask their partner to tell that part of the event (e.g., using phrases, such as "You remember this better than me, why don't you explain it" or "Do you want to explain this? I know you like telling this story"). Finishing each other's sentences was the number of times one member of the pair started saying something and then the other member of the pair interrupted and spontaneously finished off their sentence (e.g., one member of the pair might start saying "We went on the banana boat and...", then the second member of the pair will complete the sentence and say “... and we fell off into the cold water"). All four of these dependent variables were deemed appropriate for measuring transactive memory based on existing memory literature (e.g. Hollingshead, 1998; Wegner, 1987; Driskell et al., 2012).

A second coder, also blind to the hypotheses and veracity status of the pairs, coded 16 of the 46 transcripts for the total number of times each of the four dependent variables occurred. Intra-class correlation coefficients (ICCs) were then calculated between the two individual raters. The inter-rater reliability between the two coders was very good with each of the ICCs demonstrating good agreement between the two raters (posing questions to one another: $\mathrm{ICC}=.95$; providing cues to one another: $\mathrm{ICC}=.87$; handing over remembering responsibility: $\mathrm{ICC}=.62$; finishing each other's sentences: $\mathrm{ICC}=.92)$. The ICC for the handing over of remembering responsibility variable was not as high as the other three variables because this verbal transition did not occur often within the data set.

\section{Anticipated Questions: Pilot Study}


A pilot study was conducted to investigate the Expectedness of each of the six interview questions when participants were informed that they were going to be interviewed alongside their partner about their relationship. The Expectedness of the interview questions was measured because if participants had expected to be asked a specific question, they may have developed a pre-planned answer when given the opportunity to prepare for the interview, which may have then affected participants' responses and interactions whilst answering the questions. Twenty participants were recruited with a mean age of 34.00 years $(S D=12.61)$ : 11 were male and nine were female. No participants from the main study took part in this pilot study. Each participant was given a brief summary of the present experiment. After reading the summary, participants were given a short questionnaire in which they were asked to rate on a Likert scale of 1 (anticipated) to 7 (not anticipated) the extent to which they would expect that each of the six interview questions, used in the present experiment, would be asked during an interview with their partner regarding their relationship. Thus the higher the score, the less the question was expected. Table 1 shows the Expectedness of each of the six interview questions used during this experiment. The three interview questions with the lowest Expectedness scores were then categorised as the anticipated interview questions, and the three interview questions with the highest Expectedness scores were then categorised as the unanticipated interview questions. Eight new variables were then computed for each pair: Total frequency for each of the four dependent variables across the three anticipated questions only, and total frequency for each of the four dependent variables across the three unanticipated questions only.

\section{Results}

\section{Pre-Interview Questionnaire}

Five one-way ANOVAs were conducted to examine if there was a significant difference between truth-tellers and liars in terms of how they rated their preparation 
discussion prior to being interviewed. There was no significant difference between truthtellers and liars in terms of how they rated their preparation discussion in terms of thoroughness $\left(F(1,90)=0.926, p=.339\right.$, eta $\left.^{2}=.010, d=0.20\right)$, sufficiency $(F(1,90)=$ $0.011, p=.918$, eta $\left.^{2}=.000, d=0.03\right)$, and how good they found it $(F(1,90)=0.959, p=$ .330, eta $\left.^{2}=.011, d=0.20\right)$. However, liars rated the preparation discussion as more useful $(M$ $=5.89, S D=.97,95 \% \mathrm{CI}[5.41,6.36])$ than truth-tellers $(M=4.15, S D=1.99,95 \% \mathrm{CI}[3.69$, 4.60]), $F(1,90)=27.645, p<.001, e^{2} a^{2}=.235, d=1.11$. Liars also stated that they discussed with their partner about what to say during the interview significantly more thoroughly $(M=$ $5.45, S D=.90,95 \%$ CI $[5.06,5.89])$ than truth-tellers $(M=3.86, S D=1.62,95 \%$ CI $[3.47$, $4.24]), F(1,90)=33.304, p<.001, e^{2} a^{2}=.270, d=1.21$.

\section{Post-Interview Questionnaire: Motivation, Manipulation Checks, and Collective Interviewing}

The vast majority of participants indicated that they were motivated to appear convincing during the interview, with $80.3 \%$ of the sample scoring 5 or higher on the 7 -point Likert scale. Liars were significantly more motivated $(M=6.09, S D=.86,95 \%$ CI [5.60, 6.58]) than truth-tellers $(M=4.85, S D=2.10,95 \% \mathrm{CI}[4.39,5.32])$ to appear convincing, $F$ $(1,90)=13.188, p<.001$, eta $^{2}=.128, d=.77$. In terms of confidence, truth-tellers reported that they were more confident $(M=6.04, S D=1.37,95 \%$ CI $[5.61,6.48])$ than liars $(M=$ $4.48, S D=1.68,95 \% \mathrm{CI}[4.02,4.93])$ that they would receive $£ 5, F(1,90)=24.206, p<$ $.001, e t a^{2}=.212, d=1.02$. Truth-tellers were also more confident $(M=2.71, S D=1.73,95 \%$ CI $[2.26,3.16])$ than liars $(M=4.36, S D=1.40,95 \%$ CI $[3.89,4.84])$ that they would not have to write a statement, $F(1,90)=25.262, p<.001$, eta ${ }^{2}=.219, d=1.05$.

A one-way ANOVA further showed that liars found being interviewed together significantly more difficult than truth-tellers $(M=3.09, S D=1.80,95 \%$ CI $[2.57,3.62]$ and 
$M=2.10, S D=1.70,95 \% \mathrm{CI}[1.60,2.61]$, respectively), $F(1,90)=7.286, p=.008, e t a^{2}=$ $.075, d=.57$.

Finally, two one-way ANOVAs showed that truth-tellers $(M=98.96 \%, S D=3.71$, $95 \%$ CI $[94.11,103.80])$ reported to stay closer to the truth than liars $(M=51.82 \%, S D=$ $24.14,95 \%$ CI $[46.76,56.88]), F(1,90)=200.269, p<.001, e^{2} a^{2}=.690, d=2.73$, and liars $(M=51.14 \%, S D=25.26,95 \%$ CI $[45.85,56.42])$ reported to lie significantly more than truth-tellers $(M=0.83 \%, S D=3.47,95 \%$ CI $[-4.23,5.89]), F(1,90)=186.649, p<.001$, $e t a^{2}=.675, d=2.79$.

\section{Occurrence of Cues}

Someone could argue that for a cue to become a useful indicator of truthfulness it should occur frequently amongst truth-tellers. That is, it could be that a cue is more frequently used by truth-tellers than liars, but if only a small minority of truth-tellers use that particular cue then it is of limited value in lie detection as the absence of the cue does not provide meaningful information. Therefore we measured the occurrence of each of the transactive memory cues which were as follows: All 46 pairs (100\% of lying pairs and 100\% of truth-telling pairs) posed questions to one another at least twice during the interview; 32 out of 46 pairs (36.36\% of lying pairs and $100 \%$ of truth-telling pairs) provided cues to one another at least once during the interview; 10 out of 46 pairs (4.55\% of lying pairs and $37.5 \%$ of truth-telling pairs) demonstrated the handing over of remembering responsibility at least once during the interview; and 38 out of 46 pairs (63.64\% of lying pairs and $100 \%$ of truthtelling pairs) finished each other's sentence at least once during the interview. These percentages indicate that, perhaps with the exception of handing over of remembering responsibility, the transactive memory cues, thought to be used by truth-telling pairs, were indeed used by the truth-tellers in our sample.

\section{Hypotheses Testing: Transactive Memory}


A 2x2 mixed-design MANOVA was conducted with Veracity (truth versus lie) as the between-subjects factor, Expectedness (anticipated interview questions versus unanticipated interview questions) as the within-subjects factor, and (1) posing questions to one another, (2) providing cues to one another, (3) handing over of remembering responsibility, and (4) finishing each other's sentences as the dependent variables. The MANOVA revealed a significant multivariate main effect for Veracity, Wilks' $\lambda=.420, F(4,41)=14.181, p<$ .001, eta $^{2}=.580$. Significant univariate main effects for Veracity were obtained for all four dependent variables: Posing questions to one another, $F(1,44)=6.319, p=.016$, eta $^{2}=.126$, $d=.75$; providing cues to one another, $F(1,44)=16.937, p<.001$, eta $^{2}=.278, d=1.23$; handing over of remembering responsibility, $F(1,44)=7.513, p=.009$, eta $^{2}=.146, d=.83$; and finishing each other's sentences, $F(1,44)=47.217, p<.001$, eta ${ }^{2}=.518, d=2.05$. In support of Hypotheses 1 to 4, truth-telling pairs, more than lying pairs, posed questions to one another $(M=15.83, S D=10.62,95 \%$ CI $[12.27,19.40] ; M=9.41, S D=5.80,95 \%$ CI [5.69, 13.13]), provided cues to one another $(M=3.79, S D=2.87,95 \%$ CI $[2.82,4.77] ; M=0.91$, $S D=1.66,95 \% \mathrm{CI}[-0.11,1.93])$, handed over remembering responsibility $(M=0.63, S D=$ $.97,95 \%$ CI $[0.33,0.92] ; M=0.05, S D=.21,95 \%$ CI $[-0.26,0.35])$, and finished each other's sentences $(M=5.92, S D=2.95,95 \%$ CI $[4.95,6.89] ; M=1.14, S D=1.46,95 \% \mathrm{CI}$ $[0.12,2.15])$. The MANOVA also revealed a significant multivariate main effect for Expectedness, Wilks' $\lambda=.798, F(4,41)=2.747, p=.041, e t a^{2}=.211$, but at a univariate level no significant effects for Expectedness were obtained for any of the dependent variables ( $F$-values ranged from .010 - 2.765; $p$-values ranged from .103 - .919). The multivariate Expectedness $X$ Veracity interaction effect was not significant, Wilks' $\lambda=.836, F(4,41)=$ $2.014, p=.110, e t a^{2}=.164$, nor were any of the four univariate effects for the Expectedness $\mathrm{X}$ Veracity interaction ( $F$-values ranged from $.031-3.270 ; p$-values ranged from .077 $.862)$. 
Discriminant analyses were conducted on each of the significant dependent variables separately to investigate the nature of their relationship with Veracity. The individual discriminant analyses revealed that all four dependent variables were individually significant predictors of Veracity (see Table 2). The cross-validated classification results reveal that finishing each other's sentences in particular was a diagnostic cue to deceit with $87 \%$ of truth-tellers and liars classified correctly based on this cue.

\section{Truth-telling Pairs' Relationship Status}

Pearson's correlational analyses were conducted to test the association between relationship length and each of the four dependent variables. The correlations revealed that there were no significant associations between relationship length $(M=41.92, S D=44.74)$, and posing questions to one another, $r(22)=-.192, p=.369$; providing cues to one another, $r(22)=-.339, p=.105$; handing over remembering responsibility, $r(22)=-.191, p=.371$; and finishing each other's sentences, $r(22)=-.218, p=.307$.

\section{Lying Pairs' Friendship Status}

Analyses from the liars' self reports about how friendly they actually were as a pair indicated that the lying pairs reported being friendlier than was desired for the inclusion criteria of this study. That is, they were recruited as a pair only if they stated they were friends who were of the same sexual orientation, who had never been intimate, never been in a romantic relationship, and never lived together. However, liars obtained a mean of 5.73 (SD $=.95,95 \% \mathrm{CI}[5.44,6.02])$ for friendliness on a Likert scale of 1 (strangers) to 7 (best friends); a mean of $4.91(S D=1.25,95 \%$ CI $[4.53,5.29])$ for intimacy on a Likert scale of 1 (distant) to 7 (intimate); a mean of $5.91(S D=1.07,95 \%$ CI $[5.58,6.24])$ for the importance of their friendship with their interview partner on a Likert scale of 1 (unimportant) to 7 (important); and a mean of $6.07(S D=1.21,95 \%$ CI $[5.70,6.44])$ for how trusting they were of their partner on a Likert scale of 1 (distrusting) to 7 (trusting). Despite this, Veracity still 
had a significant effect on the frequency of each of the four verbal transitions, demonstrating that even when good friends lie together, signs of truthfulness still emerge in a collective interview situation. Furthermore, Pearson's correlational analyses were conducted to test the association between friendship-closeness and each of the four dependent variables. The correlations revealed that there were no significant associations between friendship-closeness $(M=22.61, S D=3.27)$, and posing questions to one another, $r(20)=.155, p=.492$; providing cues to one another, $r(20)=.300, p=.174$; and finishing each other's sentences, $r(20)=.182, p=.419$. However, the correlations did reveal a significant association between friendship-closeness and the handing over of remembering responsibility, $r(20)=-.554, p=$ .007. This significant finding needs to be interpreted with caution because the chances of making a Type I Error are increased due to multiple correlations being conducted at the same time.

Pearson's correlational analyses were also conducted to test the association between friendship length and each of the four dependent variables. The correlations revealed that there were no significant associations between friendship length $(M=14.39, S D=14.30)$, and posing questions to one another, $r(20)=.197, p=.379$; providing cues to one another, $r(20)=.345, p=.116$; handing over remembering responsibility, $r(20)=-.131, p=.561$; and finishing each other's sentences, $r(20)=-.152, p=.499$. The absence of significant correlations in both truth-tellers and liars suggest that it is Veracity and real shared events that influenced the emergence of the transactive memory cues rather than the relationship status of the pairs.

\section{Discussion}

\section{Transactive Memory Variables Differentiate Truth-tellers from Liars}

Truth-telling pairs posed questions to one another to check information or find out information, provided cues to one another, handed over remembering responsibility, and 
finished each others' sentences significantly more than lying pairs, supporting Hypotheses 1 to 4 . The effect sizes were large (ranging from $d=.75$ to $d=2.05$ ) suggesting that each of the verbal transitions should be easily identified and taught to investigators (e.g., police interviewers, fraud investigators, and immigration officers). Additionally, the findings were not dependent upon the Expectedness of the interview questions. Hence, the four verbal transitions were elicited by truth-telling pairs and not elicited by lying pairs regardless of whether the interview question was anticipated or unanticipated. This is a positive finding because it suggests that the signs of truthfulness measured in the present experiment will not be dependent upon the Expectedness of the interview question suggesting that the four verbal transitions are robust indicators of truthfulness.

The truth-telling pairs did illustrate more interactive and communicative behaviours in comparison to lying pairs who worked more on an individual basis in alignment with previous collective interviewing studies (Driskell, et al., 2012; Jundi et al., 2013a; Jundi et al., 2013b; Vrij et al., 2012). Although previous research suggests that liars plan what to say to expected questions (Vrij et al., 2010), this study implies lying pairs do not plan how to interact or communicate with one another during a collective interview, which makes it more difficult for them to behave like truth-telling couples when answering both expected and unexpected interview questions. Additionally, the natural recall of shared events from the truth-telling couples' transactive memory system means that they unconsciously interact and increase their retrieval of information together (Hollingshead, 1998) which occurs regardless of whether the interview question is anticipated or unanticipated. Overall, the present experiment focused on the differences between truth-tellers and liars based upon memory research, and demonstrated that memory, particularly transactive memory, can be used as a process for eliciting signs of truthfulness that are not influenced by interview question type.

\section{Importance of Memory in Detecting Deception}


It is widely acknowledged that memory plays an important role in deception (Sporer \& Schwandt, 2006; Verschuere, Ben-Shakhar, \& Meijer, 2011; Walczyk, Igou, Dixon, \& Tcholakian, 2013). Verbal veracity assessment tools, such as Reality Monitoring, are very much based on memory and postulate that memories of actual events differ from fabrications in predictable ways, including in terms of sensory or affective information (Johnson \& Raye, 1998). However, in deception research memory is often also viewed as a 'problem'. If truthtellers do not remember accurately or efficiently then their answers may sound like liars' answers because their answers will be vague and less detailed (Sporer \& Schwandt, 2006; Walczyk et al., 2013). If liars do not remember accurately and efficiently then their physiological responses may look similar to those of truth-tellers because they will not recognise the relevant items in a Concealed Information Polygraph Test (Verschuere et al., 2011). The present experiment demonstrated that there is a good opportunity to differentiate truths from lies if truth-tellers do not remember clearly, because the cues identified in the present experiment will then arise.

Hence, as opposed to truth-tellers sounding like liars due to providing a lack of detail, liars can be classified correctly because they will lack the presence of each of the verbal transitions. Thus, they will rarely pose questions to one another, provide cues to one another, hand over remembering responsibility, and finish each other's sentences - memory cues that will emerge from truth-tellers. Whilst liars were classified with relatively high accuracy rates for all four verbal transitions, truth-tellers were classified with low accuracy rates for three of the four verbal transitions. These low accuracy rates for truth-tellers are a concern due to the risk of false-positives (i.e., classifying a pair as deceptive when they are in fact truthful). However, the overall classification accuracy rates for these three verbal transitions were high and still significant. Additionally, the results revealed that finishing each other's sentences in 
particular was very successful in classifying correctly both truth-tellers (83.3\%) and liars $(90.9 \%)$

We realise that the memory cues we examined arise in collective interviews and may not be suitable to individual interviews. In the latter interview settings cues such as spontaneous corrections, admitting lack of memory, and raising doubt about one's own testimony are sometimes examined. They are part of Criteria-Based Content Analysis (CBCA; Köhnken, \& Steller, 1988) and truth-tellers include such cues more often than liars do (DePaulo et al., 2003; Vrij, 2008b). However, we believe that these cues are less diagnostic than the collective cues we measured in the present experiment. For example, Vrij (2008b) reported that spontaneous corrections emerged as a diagnostic cue to deceit in only eight of the 26 studies (31\%) in which they were examined. Similarly, admitting lack of memory emerged as a cue to deceit in nine out of 23 studies (39\%) and raising doubts in four out of 20 studies (25\%) examined. One reason is that such cues do not occur frequently in any case. Vrij (2005) reviewed CBCA field studies and noted that spontaneous corrections, admitting lack of memory, and raising doubt about someone's own testimony appeared in only a minority of the statements that were analysed (in $40 \%, 46 \%$ and $4 \%$ of the statements, respectively). The benefit of the transactive memory cues is that truth-tellers use them frequently.

\section{Practical Applications}

The immigration paradigm setting used in this experiment, in which couples were interviewed to judge whether their relationship was real or pretend, was particularly good for applying transactive memory theory because transactive memory was developed around intimate couples. This setting is becoming increasingly relevant as 'immigration' is high up the political agenda, with many Western countries trying to prevent illegal immigration. 
Detecting lies in the type of citizenship interviews examined in the present experiment can serve this purpose.

The four verbal transitions identified from this experiment should work under conditions in which pairs know each other well and are being interviewed collectively about actual shared experiences. Other collective interview situations where these verbal transitions are likely to occur include couples being interviewed with the aim of adopting a child, interviews at road and airport border controls, and interviews where both members of a couple are suspects (which happens frequently in suspected fraudulent insurance claims such as car insurance, tax claims, damage to property, theft, etc). Institutions that deal with immigration, adoption, security or fraud would benefit from understanding social interactions and how pairs, specifically couples, behave together and recall information when questioned collectively. If the correct questions are asked and the collective interviewing technique applied then the transactive memory variables are likely to emerge and these will help investigators determine whether the individuals that form the pair (or group) require further questioning, either individually or again collectively.

It could be argued that the immigration paradigm will not reveal the verbal transitions identified in this study if one member of the pair is more dominant than the other, or if pair members notice 'errors' during the interview from what their partner is saying, but refrain from correcting them through fear that they will then not be believed. Recent collective interviewing studies have considered these two issues. First, a study by Vernham, Vrij, Mann, Leal and Hillman (2013) used a forced turn-taking technique that took away the control from the pair of who responded to the interview question. This technique involved the interviewer stating which of the two participants was to answer the question, and then intervening every 20 seconds by stopping whichever of the participants was responding and asking the other participant in the pair to continue from the point in which their partner was stopped. This 
continued until the pair had finished answering the question. This turn-taking technique could be applied to the current immigration scenario as a way of preventing dominant characters from influencing the findings. Second, a study by Vrij et al. (2012) demonstrated that truthtelling pairs are not afraid to correct one another, add information to each other's accounts or interrupt each other, and they do actually do this significantly more than lying pairs. Therefore, the fear that truth-telling pairs will not correct 'errors' is not warranted.

Future research should consider whether the verbal transitions identified during this experiment still emerge when close, but not intimate, friends are being interviewed together about past shared events, e.g., close friends who claim to have been to a restaurant, shopping mall, or sport venue together at the time a crime took place. Additionally, it would be interesting to explore whether the verbal transitions emerge in 'suspect-alibi' situations to help law enforcement with the identification of false alibis. The verbal transitions should emerge more distinctly if two individuals are actually describing a shared event that took place at the time the crime was being committed and to a much lesser extent if a false alibi is being provided.

\section{Methodological Considerations}

Two methodological issues deserve further discussion. First, the truth-telling pairs always told a story about their real romantic relationship, whereas the lying pairs always told a false story about a fictitious romantic relationship. This means that not only did Veracity differ between the two conditions, but so did relationship status. Therefore, it could be that the findings obtained were due to truth-telling pairs having more experience of communicating shared events with one another. However, relationship length of the truthtelling pairs and friendship length of the lying pairs was not associated with the occurrence of the dependent variables, and friendship-closeness of the lying pairs significantly correlated with only one of the four dependent variables. Since this finding could reflect a Type I Error, 
the findings suggest that friendship length and friendship-closeness of the lying pairs was not associated with the occurrence of the dependent variables which suggests that it is Veracity that influences the four verbal transitions, not relationship status.

Second, it would seem that some of the responses made by lying pairs were reflective of transactive memory processes because on occasion they did display each of the verbal transitions measured. Consequently, the study would have benefitted from the inclusion of a condition in which the lying pairs were asked to tell the truth as a way of determining whether they would have then exhibited the same communicative and interactive cues as the truth-telling pairs. This would have made it clearer as to whether the significantly reduced number of verbal transitions made by lying pairs was due to a lack of transactive memory or whether it was the consequence of some other phenomenon. Nevertheless, the fact that the lying pairs knew each other well and were probably engaging in 'embedded lies' (whereby they change specific details of a true story rather than telling a blatant lie that is entirely untruthful; Vrij et al., 2010) implies that the findings from the present experiment are likely to be related to the absence of a transactive memory system in lying pairs and the presence of one in truth-telling pairs.

\section{Conclusion}

The present experiment demonstrated that memory is important within deception research and can lead to cues indicative of truthfulness. In particular, differences between truth-tellers and liars can be elicited in the transactional information search. A collective approach fits well with the current research into memory and fills a gap within the deception literature whereby group deceit has been largely ignored. Additionally, the present experiment demonstrates the importance of exploring the whole spectrum of Veracity, not just identifying signs of deception but also signs of truthfulness.

\section{References}


Barnier, A.J., \& Sutton, J. (2008). From Individual to Collective Memory: Theoretical and Empirical Perspectives. Memory, 16, 177-182. DOI: 10.1080/09541440701828274.

Blumen, H.M., Rajaram, S., \& Henkel, L. (2013). The Applied Value of Collaborative Memory Research in Aging: Behavioral and Neural Considerations. Journal of Applied Research in Memory and Cognition, 2, 107-117. DOI:10.1016/j.jarmac.2013.03.003.

DePaulo, B. M., LeMay, C. S., \& Epstein, J. A. (1991). Effects of importance of success and expectations for success on effectiveness at deceiving. Personality and Social Psychology Bulletin, 17, 14-24. DOI: 10.1177/0146167291171003.

DePaulo, B. M., Lindsay, J. J., Malone, B. E., Muhlenbruck, L., Charlton, K., \& Cooper, H. (2003). Cues to Deception. Psychological Bulletin, 129, 74-118. DOI: 10.1037/00332909.129.1.74.

Driskell, J.E., Salas, E., \& Driskell, T. (2012). Social Indicators of Deception. Human Factors: The Journal of the Human Factors and Ergonomics Society, 54, 577-588. DOI: $10.1177 / 0018720812446338$.

Gilovuch, T., Savitsky, K., \& Medvec, V.H. (1998). The Illusion of Transparency: Biased Assessments of Others' Ability to Read One's Emotional States. Journal of Personality and Social Psychology, 75(2), 332-346. DOI: 10.1016/S00221031(03)00056-8.

Granhag, P.A., Strömwall, L.A., \& Jonsson, A.C. (2003). Partners in Crime: How Liars in Collusion Betray Themselves. Journal of Applied Social Psychology, 33, 848-868. DOI: 10.1111/j.1559-1816.2003.tb01928.x.

Harris, C.B., Paterson, H.M., \& Kemp, R.I. (2008). Collaborative Recall and Collective Memory: What happens when we remember together? Memory, 16, 213-230. DOI: 10.1080/09658210701811862. 
Hintz, V. B. (1990). Cognitive and consensus processes in group recognition memory performance. Journal of Personality and Social Psychology, 59, 705-718. DOI: 10.1037/0022-3514.59.4.705.

Hirst, W., \& Manier, D. (2008). Towards a Psychology of Collective Memory. Memory, 16, 183-200. DOI: 10.1080/09658210701811912.

Hollingshead, A. B. (1998). Retrieval processes in transactive memory systems. Journal of Personality and Social Psychology, 74, 659-671. DOI: 10.1037/0022-3514.74.3.659.

Hollingshead, A. B., \& Brandon, D.P. (2003). Potential Benefits of Communication in Transactive Memory Systems. Human Communication Research, 29, 607-615. DOI: 10.1111/j.1468-2958.2003.tb00859.x.

Johnson, M. K., \& Raye, C. L. (1998). False Memories and Confabulation. Trends in Cognitive Sciences, 2, 137-145. Retrieved from: http://www.unibielefeld.de/psychologie/ae/AE14/LEHRE/Winter0304/Johnson_Raye98.pdf.

Jundi, S., Vrij, A., Hope, L., Mann, S., \& Hillman, J. (2013b). Establishing Evidence through Undercover and Collective Intelligence Interviewing. Psychology, Public Policy, and Law, 19, 297-306. DOI: 10.1037/a0033571.

Jundi, S., Vrij, A., Mann, S., Hope, L., Hillman, J., Warmelink, L., \& Gahr, E. (2013a). Who Should I Look At? Eye Contact during Collective Interviewing as a Cue to Deceit. Psychology, Crime \& Law, DOI: 10.1080/1068316X.2013.793332.

Kassin, S.M., \& Gudjonsson, G.H. (2004). The Psychology of Confessions: A Review of the Literature and Issues. Psychological Science in the Public Interest, 5, 33-44. DOI: 10.1111/j.1529-1006.2004.00016.x.

Köhnken, G., \& Steller, M. (1988). The evaluation of the credibility of child witness statements in German procedural system. In G. Davies \& J. Drinkwater (Eds.), The child witness: Do the courts abuse children? (Issues in Criminological and Legal 
Psychology, no. 13) (pp. 37-45). Leicester, United Kingdom: British Psychological Society.

M'Gloin, J.M., \& Piquero, A.R. (2009). 'I Wasn’t Alone': Collective Behaviour and Violent Delinquency. Australian \& New Zealand Journal of Criminology, 42, 336-353. DOI: 10.1375/acri.42.3.336.

Porter, S., \& Yuille, J.C. (1996). The Language of Deceit: An Investigation of the Verbal Clues to Deception in the Interrogation Context. Law and Human Behaviour, 20, 443458. DOI: 10.1007/BF01498980.

Rajaram, S. (2011). Collaboration Both Hurts and Helps Memory: A Cognitive Perspective. Current Directions in Psychological Science, 000, 1-6. DOI: 10.1177/0963721411403251.

Rajaram, S., \& Pereira-Pasarin, L.P. (2010). Collaborative Memory: Cognitive Research and Theory. Perspectives on Psychological Science, 5, 649-663. DOI: $10.1177 / 1745691610388763$.

Ross, M., Blatz, C.W., \& Schryer, E. (2008). Social Memory Processes. In H.L. Roediger (Ed.), Learning and Memory - A Comprehensive Reference, Volume 2: Cognitive Psychology of Learning (pp. 911-926). New York, NY: Elsevier.

Sporer, S. L., \& Schwandt, B. (2006). Paraverbal Indicators of Deception: A meta-analytic synthesis. Applied Cognitive Psychology, 20, 421-446. DOI: 10.1002/acp.1190.

Strömwall, L.A., Granhag, P.A., \& Jonsson, A.C. (2003). Deception Among Pairs: "Let's Say We Had Lunch and Hope They Will Swallow It!” Psychology, Crime \& Law, 9, 109124. DOI: $10.1080 / 1068316031000116238$.

Van Mastrigt, S.B., \& Farrington, D.P. (2009). Co-offending, Age, Gender and Crime Type: Implications for Criminal Justice Policy. British Journal of Criminology, 49, 552-573. DOI: 10.1093/bjc/azp021. 
Vernham, Z., Vrij, A., Mann, S., Leal, S., \& Hillman, J. (2013). Collective Interviewing: Eliciting Cues to Deceit using a Turn-Taking Approach. Manuscript under review.

Verschuere, B., Ben-Shakhar, G., \& Meijer, E. (2011). Memory detection: Theory and application of the concealed information test. Cambridge, England: Cambridge University Press.

Vrij, A. (2005). Criteria-Based Content Analysis: A qualitative review of the first 37 studies. Psychology, Public Policy, and Law, 11, 3-41. DOI: 10.1037/1076-8971.11.1.3.

Vrij, A. (2008a). Detecting Lies and Deceit: Pitfalls and Opportunities ( $2^{\text {nd }}$ Ed.). Chichester: John Wiley \& Sons.

Vrij, A. (2008b). Nonverbal Dominance versus Verbal Accuracy in Lie Detection: A Plea to Change Police Practice. Criminal Justice and Behaviour, 35, 1323-1336.

Vrij, A., Jundi, S., Hope, L., Hillman, J., Gahr, E., Leal, S., Warmelink, L., Mann, S., Vernham, Z., \& Granhag, P.A. (2012). Collective Interviewing of Suspects. Journal of Applied Research in Memory and Cognition, 1, 41-44. DOI: 10.1016/j.jarmac.2011.12.002.

Vrij, A., Leal, S., Granhag, P.A., Mann., S., Fisher, R.P., Hillman, J., \& Sperry, K. (2009). Outsmarting the Liars: The Benefit of Asking Unanticipated Questions. Law and Human Behaviour, 33(2), 159-166. DOI: 10.1007/s10979-008-9143-y.

Vrij, A., Mann, S., Leal., S., \& Granhag, P.A. (2010). Getting into the Minds of Pairs of Liars and Truth-tellers: An Examination of Their Strategies. The Open Criminology Journal, 3, 17-22. DOI: 10.2174/1874917801003010017.

Walczyk, J. J., Igou, F. P., Dixon, A. P., \& Tcholakian, T. (2013). Advancing lie detection by inducing cognitive load on liars: A review of relevant theories and techniques guided by lessons from polygraph-based approaches. Frontiers in Psychology, 4, 14. DOI: 10.3389/fpsyg.2013.00014. 
Wegner, D. M. (1987). Transactive Memory: A contemporary analysis of the group mind. In B. Mullen \& G.R. Goethals (Eds.), Theories of group behaviour (pp. 185-208). New York: Springer-Verlag.

Wegner, D.M., Erber, R., \& Raymond, P. (1991). Transactive Memory in Close

Relationships. Journal of Personality and Social Psychology, 61, 923-929. Retrieved from: http://www.wjh.harvard.edu/ wegner/pdfs/Wegner,Erber,\&Raymond1991.pdf.

Wegner, D.M., Giuliano, T., \& Hertel, P.T. (1985). Cognitive Interdependence in Close

Relationships. In W.J. Ickes (Ed.), Compatible and Incompatible Relationships (pp. 253-276). New York: Springer-Verlag. 
Table 1: Expectedness score for each of the six interview questions used in this experiment.

\section{Interview Question}

Expectedness

Score
Expectedness

Category
1. 'Can you describe in as much detail as possible how and when you first met. Please give as much information as you can about your first interaction, the location you were at, and so on'.
1.20

2. 'Can you describe in as much detail as possible your first date and when this was. Think about the location and the sights and sounds you experienced'.

3. 'Describe your home'.
Anticipated

question
Anticipated

question

question

4. 'Please draw the exterior of your bedroom on this piece of A3 paper... Now describe in as much detail as you can your bedroom starting from the left-hand wall and moving all the way around the outline. Please describe everything including furnishings, decor etc'.

5. 'Describe a recent memorable day that you spent together hour by hour (this must not be your wedding day if you are married)'.

6. 'Can you describe in as much detail as possible your last holiday or 2.20 trip away together? Please give as much information as you can about the location, what you did, the sights you experienced, and so on'.
3.95

Unanticipated

question

question 
Table 2: Classification results for each of the four significant dependent variables.

\begin{tabular}{|c|c|c|c|c|c|}
\hline Transactive Memory Variable & Chi-Square & $\begin{array}{l}\text { Wilks' } \\
\text { Lambda } \\
\text { (significance) }\end{array}$ & $\begin{array}{l}\text { Total } \\
\text { percentage } \\
\text { of cases } \\
\text { correctly } \\
\text { classified }\end{array}$ & $\begin{array}{l}\text { Percentage } \\
\text { of truth- } \\
\text { tellers } \\
\text { correctly } \\
\text { classified }\end{array}$ & $\begin{array}{l}\text { Percentage } \\
\text { of liars } \\
\text { correctly } \\
\text { classified }\end{array}$ \\
\hline Posing questions to one another & 5.837 & .874 (.016) & $65.2 \%$ & $54.2 \%$ & $77.3 \%$ \\
\hline Providing cues to one another & 14.166 & $.722(<.001)$ & $71.7 \%$ & $54.2 \%$ & $90.9 \%$ \\
\hline $\begin{array}{l}\text { Handing over remembering } \\
\text { responsibility }\end{array}$ & 6.857 & .854 (.009) & $65.2 \%$ & $37.5 \%$ & $95.5 \%$ \\
\hline Finishing each other's sentences & 31.714 & $.482(<.001)$ & $87.0 \%$ & $83.3 \%$ & $90.9 \%$ \\
\hline
\end{tabular}

